\title{
DISCUSSION
}

\section{Precompression design for secondary settlement reduction}

\author{
E. E. AlONSO, A. GENS and A. Lloret (2000). Géotechnique 50, No. 6, 645-656
}

\section{Nash, University of Bristol}

The authors have presented a very interesting case study that supplements the meagre collection of such field data in the literature. The writer has recently considered the similar problem of using temporary surcharge to reduce the long-term settlement beneath embankments on soft clay (Nash \& Ryde, 2001). While the authors have adopted a conceptual model in which creep strain and void ratio exhibit a linear relationship with time, in using such a model there is frequently difficulty in deciding the time origin, particularly if the time for primary consolidation is long.

As noted by the authors, when considering the effectiveness of precompression for secondary settlement reduction (Bjerrum (1972) proposed the use of a conceptual isotache model similar to that shown in Fig. 17. Here the parallel lines or isotaches connect soil states at which the plastic volumetric strain rate is constant. The solid line ABD in Fig. 17 indicates a path that might be followed by an element of soil loaded by an increment of total stress, $\Delta \sigma$, as it consolidates. As the effective stress increases from the initial state at point $A$, the creep strain rate increases as the soil state moves to the right, but the effective stress and strain rate are limited by the ability of the pore water to escape. After further consolidation the strain rate decreases until excess pore pressures have dissipated at point B, after which creep continues at decreasing rates towards point $D$. If the loading is reduced with a consequential reduction of effective stress, say from $\mathrm{C}$ to $\mathrm{E}$, there may initially be some elastic swelling followed by a resumption of creep compression, with the creep rate reduced to that of the corresponding isotache at E. Thereafter creep continues at a reduced rate towards point $F$. Although it is known that in practice a large reduction of stress may result in secondary swelling, in this simple isotache model there is no lower limit to creep. Several such models have been proposed, including that of Yin \& Graham (1996), which has been incorporated into a model of consolidation accelerated by vertical drains by Nash \& Ryde (2001).

This model may be used to predict the creep behaviour when the effective stress is reduced (say from point $\mathrm{C}$ to point $\mathrm{E}$ in Fig. 17). This is illustrated in Fig. 18, which shows the creep behaviour predicted for an oedometer test under constant effec-

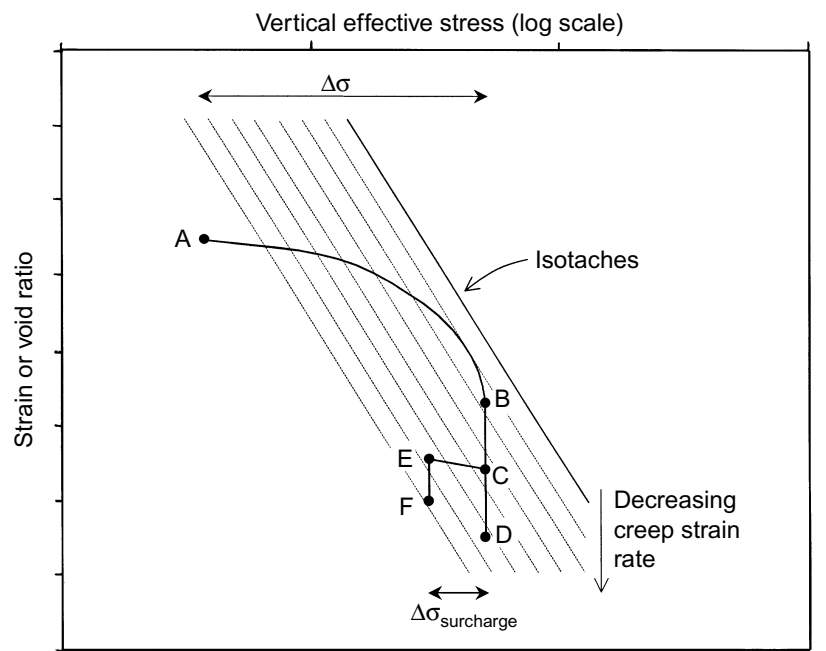

Fig. 17. Isotache model for compression of soft clays

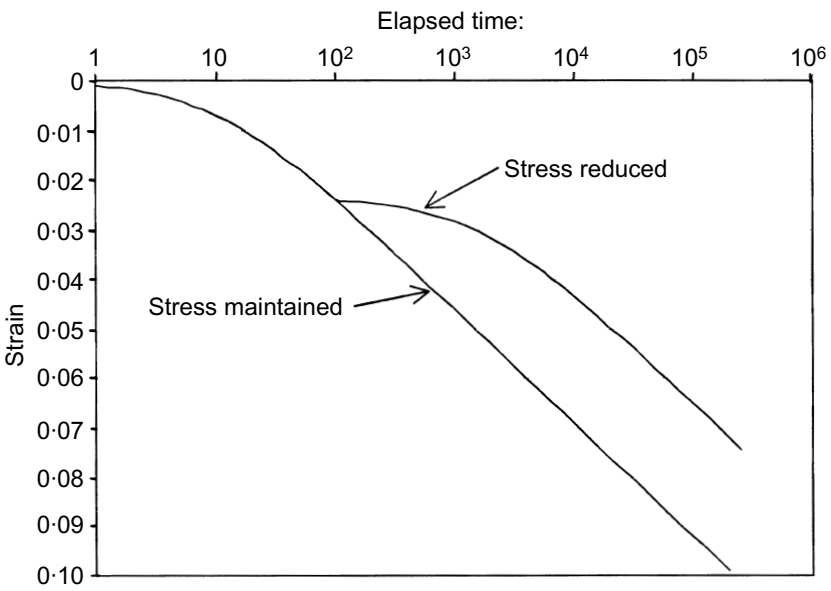

Fig. 18. Creep behaviour predicted using isotache model showing effect of reduction of applied stress

tive stress, and the effect of reducing the effective stress after an elapsed time $t=100$. It may be seen that reduction of effective stress reduces both the creep rate and the coefficient of secondary compression $C_{\alpha}$, and that $C_{\alpha}$ (but not the creep rate) gradually increases with time, behaviour that has been reported in the literature. It may also be seen that the subsequent settlement at large time is quite a significant proportion of that which would have occurred if there had not been any unloading.

The reduction of creep rate predicted by the model is related to the degree of overconsolidation achieved. Assuming that equally spaced isotaches indicate a logarithmic reduction of strain rate it may be shown from the geometry of Fig. 17 that when the effective stress is reduced from $\sigma_{1}^{\prime}$ to $\sigma_{2}^{\prime}$ :

$$
\frac{\dot{\varepsilon}_{1}}{\dot{\varepsilon}_{2}}=\frac{C_{\alpha_{1}}}{C_{\alpha_{2}}}=\left(\frac{\sigma_{1}^{\prime}}{\sigma_{2}^{\prime}}\right)^{(\lambda-\kappa) / \psi}
$$

where the values of creep rate and $C_{\alpha}$ are those just before and just after the change of stress. Here $\lambda$ and $\kappa$ are the slope of the normal consolidation and swell lines (from critical-state soil mechanics), and $\psi$, which determines the separation of the isotaches, is approximately equal to $C_{\alpha \mathrm{NC}} / 2 \cdot 3$, where $C_{\alpha \mathrm{NC}}$ is obtained for the normally consolidated soil. The parameters $\lambda, \kappa$ and $\psi$ may be obtained for example from incremental load oedometer tests, or the ratio $\psi /(\lambda-\kappa)$ may be approximated by the ratio $\left(C_{\alpha} / C_{C}\right)_{\mathrm{NC}}$, for which typical values are given by Mesri \& Godlewski (1977) and Holtz et al. (1991).

The relationship between the immediate reduction of creep rate and $C_{\alpha}$ and the degree of overconsolidation predicted by equation (4) is shown in Fig. 19 for various values of $\psi /(\lambda-\kappa)$. It is interesting to note that this is similar to that found empirically by Ladd (1971) and the authors in their Fig. 14, although the values predicted by the isotache model are independent of the surcharge time (contrary to Ladd's findings), and are smaller than those found empirically. This difference may arise because in practice determination of $C_{\alpha}$ after unloading requires measurements over a significant time period, and as noted above $C_{\alpha}$ is likely to increase with time. The writer is of the opinion that a varying $C_{\alpha}$ is not a very helpful quantity, and can more usefully be replaced by a single value that defines the spacing of the isotaches. 


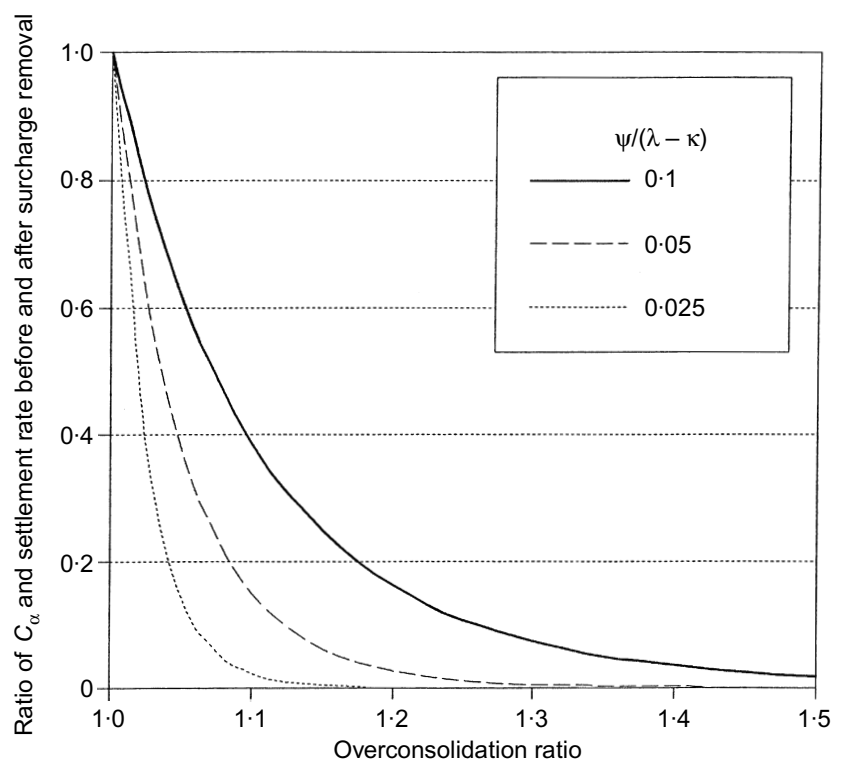

Fig. 19. Reduction of creep rate and $C \alpha$ due to overconsolidation predicted using the isotache model

In practice it may be necessary to reduce the applied stress before all excess pore pressures have dissipated, even if vertical drains are used to accelerate consolidation. The isotache model has been incorporated into a consolidation analysis, and used to predict the effect of precompression on the long-term settlement of a hypothetical test fill placed at the Bothkennar soft clay research site (Nash, 2001). The effects of a permanent loading of $100 \mathrm{kPa}$ with a temporary additional surcharge of $50 \mathrm{kPa}$ were modelled, to explore the effectiveness of the surcharge in reducing the long-term creep settlement. The analyses included vertical drains at approximately $2 \mathrm{~m}$ centres, but also considered consolidation without drains (and one case without creep). The settlement-time plots in Fig. 20 show that the long-term total settlement is independent of the time at which the surcharge is removed, but as might be expected the timing strongly influences the residual settlement after surcharge removal. Points A,
$\mathrm{B}$ and $\mathrm{C}$ in Fig. 20 indicate unloading after surcharge periods of 1,2 and 3 years respectively, and the figure shows clearly the penalty of removing the surcharge before the long-term settlement has been achieved.

Such isotache models offer a framework for interpreting field and laboratory creep data involving loading in the normally consolidated region followed by a small degree of unloading. The data given by the authors in Fig. 9 appear to be consistent with such a model. It would be interesting to plot the field and laboratory data for each depth in the form logarithm of strain rate against strain (Nash \& Ryde, 2001). Such a plot would indicate whether the separation of the isotaches (given by the slope of the lines) is indeed the same before and after removal of the surcharge as expected.

\section{T.-W. Feng. Chung Yuan Christian University, Taiwan}

The authors have presented a surcharging case history in which, in particular, both in-situ preload test and oedometer surcharging test have been carried out to study the reduction of secondary compression by overconsolidation. The term 'surcharging' denotes a special case of precompression, in that a surcharge load is removed at the end of precompression (Feng, 1991).

Rebound of the ground upon the removal of surcharge is an important aspect in using the surcharging technique to reduce the secondary compression. The deformation behaviour of the ground upon the removal of surcharge load includes primary rebound as a result of dissipation of negative pore water pressure, followed by secondary rebound, which stops when the secondary compression reappears (Feng, 1991; Mesri \& Feng, 1991). The time of the end of primary rebound can be predicted by using the Terzaghi theory of one-dimensional consolidation (Mesri et al., 1978). The time of the end of secondary rebound - that is, the time of reappearance of secondary compression - can be predicted from an empirical correlation developed using both field and laboratory data (Feng, 1991). It was found from the empirical data that the time of the end of secondary rebound increases significantly with an increase in the magnitude of the surcharge load. For instance, field experiences (Lea \& Brawner, 1963; Holtz \& Broms, 1972; Veder \& Prinzl, 1983; Samson, 1985; Jorgenson, 1987) show that the time of reappearance of secondary compression after the removal of surcharge is about 10-40 times the time of the end of primary rebound. It is not clear how the rebound behaviour of the ground is analysed

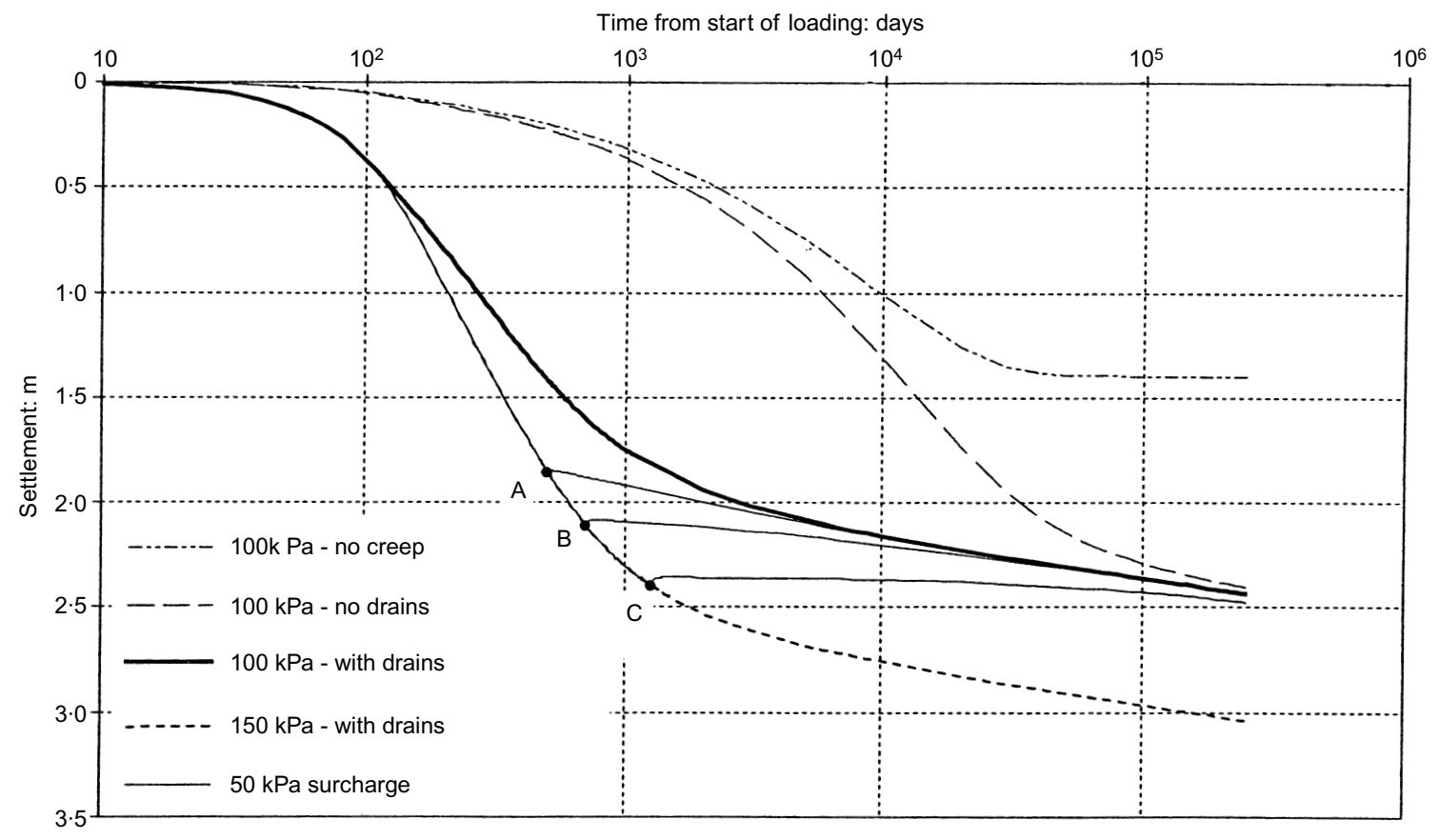

Fig. 20. Predicted time-settlement behaviour of hypothetical test fill at Bothkennar showing the effect of temporary surcharge 
or computed by the authors. It seems from Fig. 15 of the authors' paper that only the primary rebound was dealt with.

It is not known, in relation to the in situ preload test, why the surcharge load was removed as late as 2 years after the construction of the embankment. The reason for raising this question is that the curves of measured settlement against time as shown in Fig. 9(a) indicate a maximum time of the end of primary consolidation of around 100 days. It is rare to leave the surcharge load in place for such a long time. It is more efficient to reduce the secondary settlement by using a higher surcharge load and a shorter precompression time. It is unfortunate that the preload test was concluded only 8 months after the removal of surcharge load. This means that caution should be taken in using the data presented in Fig. 14. Since the preload test has already been concluded, there is no way to find out how close the predicted post-surcharge secondary settlement is to the measured postsurcharge secondary settlement. It may be mentioned that the writer and co-workers successfully analysed the post-surcharging secondary settlement at the Ska-Edeby test fill site (Feng, 1991; Mesri et al., 1994), at which the ground settlement measurement programme was maintained for 30 years.

There are other suggestions for the attention of the authors. In Fig. 5(a) it can be seen that the surcharge load was removed after 3 days of oedometer consolidation, but information on the time of the end of primary consolidation is absent. The only clue from Fig. 5(a) is that it must be less than 1000 seconds. Thus it can be concluded from this observation that at least two $\log$ cycles of secondary compression had occurred before the removal of surcharge load. The contribution of the long-term secondary compression to the increase in OCR should be added to the OCR induced by the removal of surcharge load to obtain an actual OCR value. The actual OCR values should then be used to correlate with the ratio $C_{\alpha} / C_{\alpha \mathrm{NC}}$.

Finally, the definition of the ratio $C_{\alpha} / C_{\alpha \mathrm{NC}}$, as used in both Fig. 5(b) and Fig. 14, is not consistent with the literature. In precompression operations with a surcharge load, the permanent (final) load after the removal of surcharge is the same as the final load without surcharge. Therefore both $C_{\alpha}$ and $C_{\alpha \mathrm{NC}}$ are in fact measured under the same effective stress, and are used conventionally to evaluate the effectiveness of surcharging to reduce secondary compression. Apparently, the authors did not follow this practice.

\section{Authors' reply}

The authors appreciate the interest of the writers in the work presented, and welcome the opportunity to discuss further some of the issues raised in the paper.

\section{To D. Nash}

One of the main points of the paper is to show how site investigation data and field monitoring records are used in design and prediction. In this context, the conceptual model adopted was kept simple since the practical nature of the problem dominated the entire modelling approach. One of the major concerns was to identify in situ the main factors controlling long-term secondary behaviour of the deep soil profile under study.

The authors also maintain an interest in fundamental issues related to long-term deformation of clays. Empirical models such as Bjerrum's (1972) isotache concept are probably useful, especially for low OCR, as the writer notes. Bjerrum's conceptual model predicts a progressive increase of the $C_{\alpha}$ coefficient after a reduction in effective stress. $C_{\alpha}$ will eventually recover the NC value, previous to unloading, as Fig. 18 indicates. Although there is some experimental evidence in support of this trend there are also long-term field observations that show that $C_{\alpha}$ is consistently reduced to a fraction of the NC value. This is shown, for instance, in the data presented by Monoi \& Fukuzawa (1998) for the sites 'A' Sapporo and ' $B$ ' Chiba. In the second site, for example, the average $C_{\alpha}$ value, which may be derived 7 years after unloading, seems to be stabilised at a value that is only $8 \%$ of the NC $C_{\alpha}$ value previous to the unloading. Any potential subsequent increase in the $C_{\alpha}$ coefficient would correspond to times too long to be of practical concern.

The authors share the writer's opinion that $C_{\alpha}$ is not a convenient parameter, especially when considering creep phenomena from a fundamental point of view. In a recent work aimed at deriving more accurate models for secondary consolidation strains (Alonso et al., 2001), it was found that secondary strains depend on the reloading stress increment ratio, on the initial strain rate, and on time. The model developed in the work just mentioned is based on the original ideas of Mitchell (1981) (secondary strain rates and time, both in log scale, are linearly related), and on a fairly comprehensive laboratory test programme involving long-term oedometer tests for several combinations of preconsolidation, unloading and reloading (final) stresses.

This recent model, as well as Bjerrum's (1972) isotache concept, remain largely empirical and have significant limitations. One is mentioned in the writer's discussion and refers to the intensity of the unloading step (or OCR). This aspect has been recently investigated by means of a series of long-term oedometer tests. In Fig. 21 plots of vertical strain against time are given for three tests on remoulded samples of the lowplasticity clay described in the paper. The three tests maintain a common value for OCR of 2 (the initial stress, $\sigma_{\mathrm{i}}^{\prime}=0.4 \mathrm{MPa}$, was reduced to $\left.\sigma_{\mathrm{f}}^{\prime}=0.2 \mathrm{MPa}\right)$, but the loading time under $\sigma_{\mathrm{i}}^{\prime}=0.4 \mathrm{MPa}$ varied in the three tests $(10 \mathrm{~min}, 100 \mathrm{~h}$ and $500 \mathrm{~h}$ respectively). Once the transient primary swelling is essentially finished, a secondary behaviour may be observed in the three tests. This secondary behaviour is better observed in Fig. 22, where strains after unloading are plotted with a common time origin (100s after unloading). The three samples exhibit a swelling secondary behaviour. In two of them $(t=10 \mathrm{~min}$; $t=100 \mathrm{~h}$ ) the swelling strain rate decreases with time and may even reverse sign (this is the case for the specimen loaded for $t=10 \mathrm{~min}$ ), but in the specimen loaded for $500 \mathrm{~h}$ prior to unloading the swelling strain rate is approximately constant during the test period. This pattern of behaviour is not well predicted by the types of framework mentioned before.

It should be noted, also, that the initial slope of the plots of strain against $\log t$ of Fig. 22 (or initial $C_{\alpha}$ values) depend on the surcharge time, unlike equation (4). Even for small overconsolidation ratios, a changing initial $C_{\alpha}$ value with the surcharge time is also recorded, as the additional data plotted in Fig. 22 for the same soil and for OCR $=1.05$ show. These experimental results are in agreement with Ladd's (1971) findings reported in the paper (Figures 5(b) and Fig. 14).

Therefore models based on the isotache framework also have difficulties in reproducing with some generality the observed one-dimensional creep behaviour of clays. Even more sophisticated empirical expressions, rooted in direct phenomenological observations of creep behaviour under a variety of loading sequences (Alonso et al., 2001), are incapable of modelling accurately a number of settlement-swelling creep transitions.

The authors believe that a more fundamental approach, which links creep behaviour to local fluid transfer phenomena at a microstructural level, may provide more consistent results. This idea has also received attention by the authors (Alonso et al., 1991), and in a recent work (Navarro \& Alonso, 2001) a model for secondary compression of clays has been proposed in which relatively simple, yet comprehensive, models for primary/secondary behaviour of clays are presented. This approach incorporates in a natural way the transient compression-swelling secondary behaviour, when the OCR or the preloading times take arbitrary values.

\section{To T.-W. Feng}

The writer bases the main part of the discussion on a description of the deformation behaviour of soils on unloading in terms of a primary rebound, a secondary rebound and a final secondary compression. This framework is probably adequate for some ranges of OCR and preloading times. However, it is hardly a general description of the unloading behaviour of soils. 


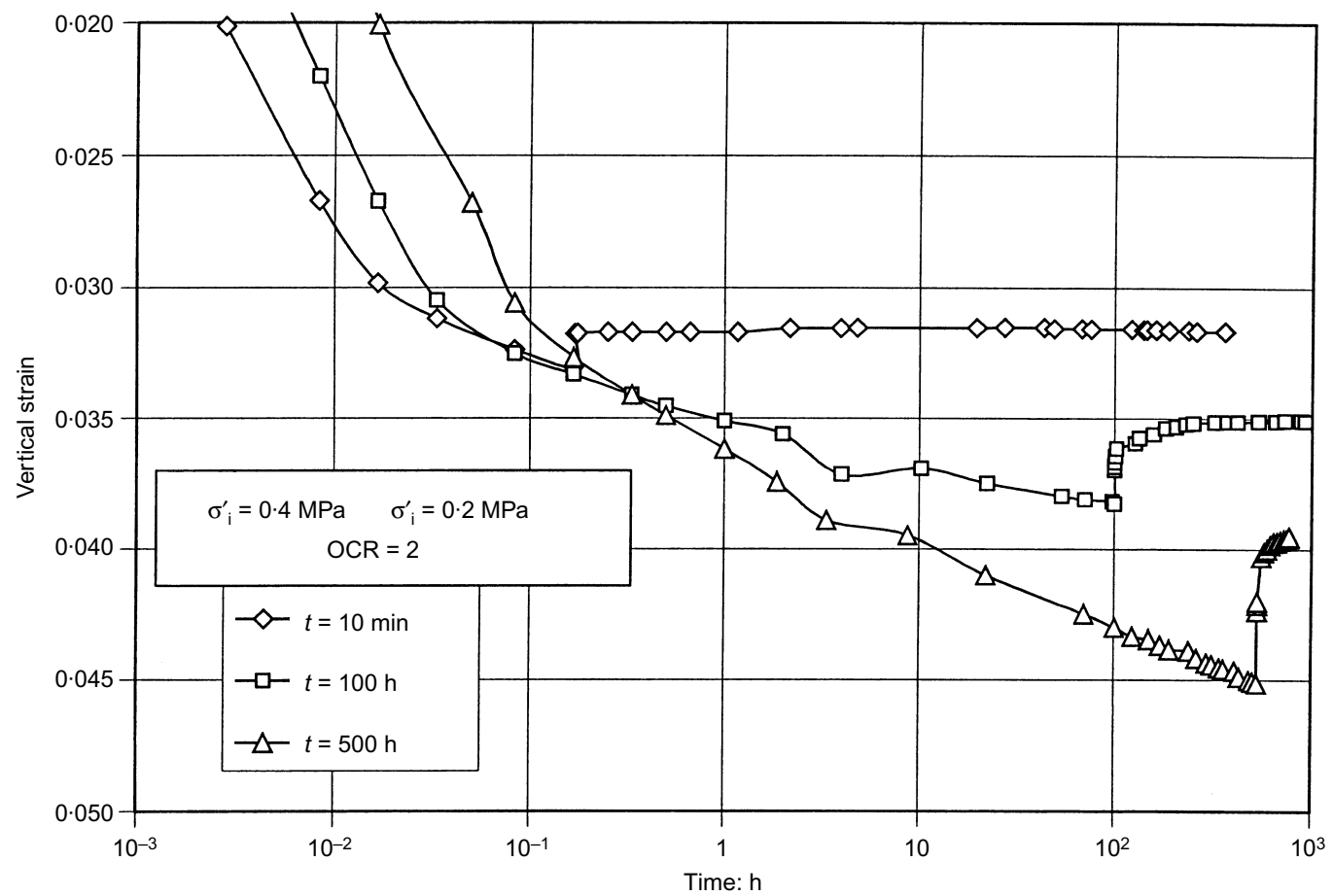

Fig. 21. Vertical strains measured in the oedometer loading-unloading tests on remoulded samples of Barcelona low-plasticity deltaic clays. Initially applied vertical stress, $\sigma_{\mathrm{i}}^{\prime}=0.4 \mathrm{MPa}$; final vertical stress, $\sigma_{\mathrm{f}}^{\prime}=0.2 \mathrm{MPa}$

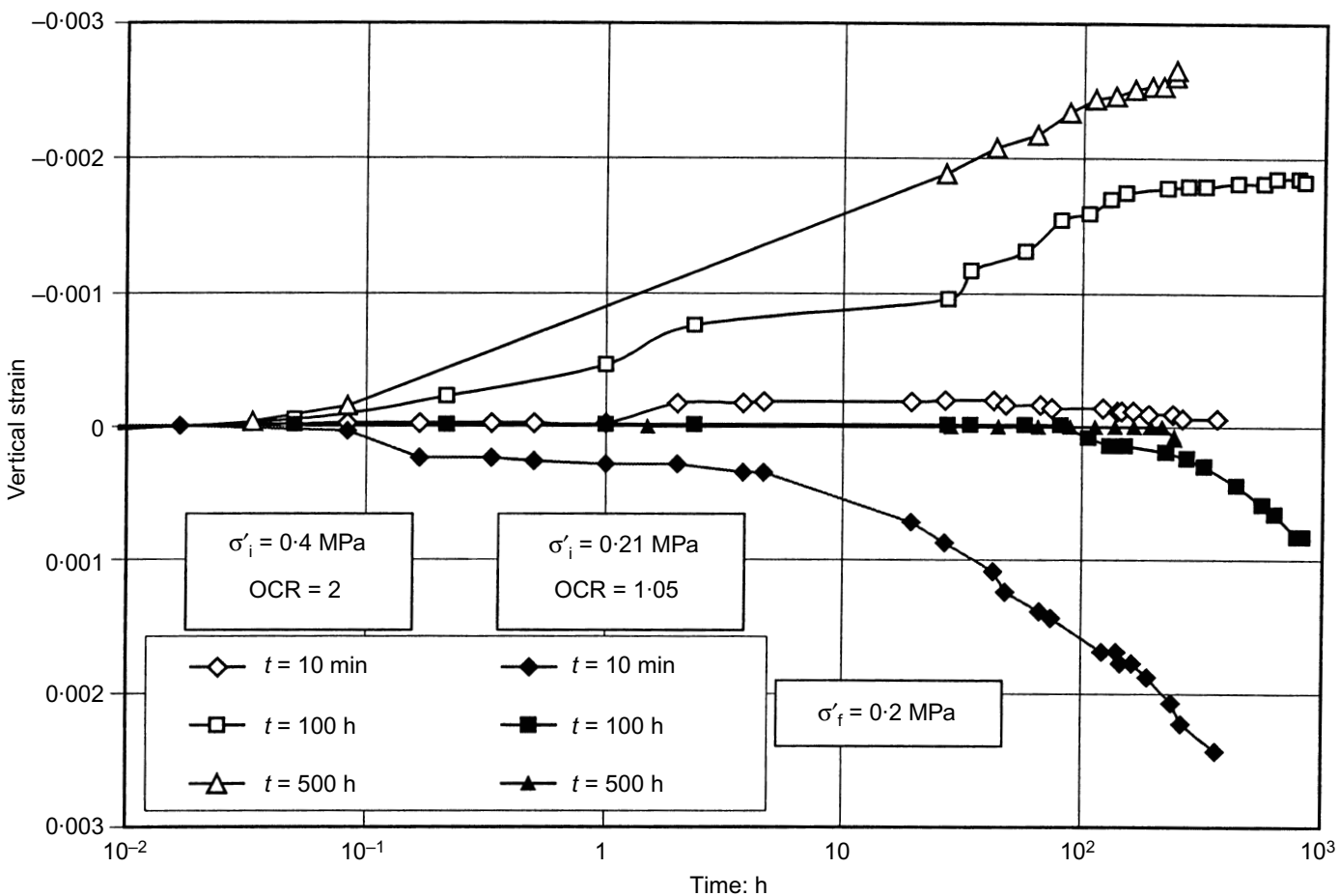

Fig. 22. Strains measured after unloading, in two series of loading-unloading tests on Barcelona low-plasticity deltaic clay for $\mathrm{OCR}=2$ and $\mathrm{OCR}=1 \cdot 05$. In all cases a constant creep stress, $\sigma_{\mathrm{f}}^{\prime}=0 \cdot 2 \mathrm{MPa}$, is applied

For instance, when OCR increases, only long-term swelling is recorded, as shown in Figs 21 and Fig. 22. The empirical law mentioned by the writer, which defines the initial time of the secondary compression as $10-40$ times the final time of the primary rebound, does not fit-even in an approximate manner-the experimental data recorded by the authors. In Fig. 21, the test for OCR $=2$ and $t=10 \mathrm{~min}$ follows a pattern of behaviour compatible with the framework mentioned above. The thickness of samples in those experiments was reduced on purpose to $8 \mathrm{~mm}$ to minimise the period of primary deforma- tion. Accurate records of the early stages of deformation immediately after loading or unloading show that the time for primary consolidation was about $100 \mathrm{~s}$ The time at which secondary compression resumes in the test $(\mathrm{OCR}=2$, $t=10 \mathrm{~min}$ ) may be located at $t=10^{5} \mathrm{~s}$, which implies a ratio $10^{5} / 10^{2}=10^{3}$ (against the 10-40 range suggested by Feng). This ratio is much higher for the test $(\mathrm{OCR}=2, t=100 \mathrm{~h})$ plotted in the same Fig. 21, and has no meaning for the test $(\mathrm{OCR}=2, t=500 \mathrm{~h})$ that only exhibits secondary expansion. As pointed out above, the authors believe that the development 
of a general framework for secondary consolidation of clays may require the incorporation of the physical phenomena underlying this type of behaviour.

Concerning the period over which the preload test was carried out, it must be pointed out that the test embankment was left in place for the maximum possible time compatible with the schedule of the project, in order to define as precisely as possible in situ primary and secondary soil deformation characteristics. Of course, the loading time of the preload test does not presuppose the time adopted for the preload design, where the usual strategy of using a higher surcharge load applied over a limited time (6 months, as indicated in Fig. 16) has been used. The unloaded trial embankment offered reliable results during eight additional months. Afterwards, construction of the designed preload embankments for the water treatment plant began to affect the test area, and measurements could no longer be used to interpret unloading effects. Naturally, this means that the effects of unloading could not be fully observed, but they will be checked in the future from the monitoring data of the water treatment plant. In summary, the preload test was a useful investigation tool, the purpose of which was to define in situ soil behaviour, and in no way was intended to follow exactly the preload design steps.

Regarding the last two points raised by the writer, the authors have plotted the data in a manner that is considered to be more relevant for the purposes of the problem considered. For instance, the question of which OCR should be used to analyse changes in $C_{\alpha}$ as a result of unloading is still an open one. In the authors' experience, the secondary deformation history cannot be interpreted on the basis of a unique relationship between rate of secondary deformation and updated OCR. An additional function of time is required to describe secondary behaviour, as the recent empirical model reported in Alonso et al. (2001) suggests. The nominal OCR, which does not require additional assumptions for its definition, was therefore used in Fig. 5(a) to plot the data. With respect to the last remark of the writer, the $C_{\alpha}$ values compared in Figures 5(a) and Fig. 14 of the paper correspond in fact to different confining stresses: the consolidation load and the load remaining after unloading. But this is precisely what is required in practice when the effects of partial unloading are investigated. Available field creep deformation records provide information for the trial embankment load before and after unloading. If the same practice is followed in laboratory tests, oedometer and field data can in principle be represented together in the same plot, as in Fig. 14. As a final comment, the practical approach followed by the authors, which relies on a simple $C_{\alpha}$ model for secondary soil behaviour, is probably suited only for small OCR values. Under these circumstances, the confining effective stresses before and after unloading are relatively close, and their effect on the creep coefficient $C_{\alpha}$ should be of minor relevance.

\section{REFERENCES}

Alonso, E. E., Gens, A. \& Lloret, A., (1991). Double structure model for the prediction of long-term movements in expansive materials. In
Computer methods and advances in geomechanics (eds G. Beer, J. R. Booker and J. P. Carter), Vol. 1, pp. 541-548. Rotterdam: Balkema.

Alonso, E. E., Lloret, A., Gens, A. \& Salvadó, M. (2001). Overconsolidation effects on secondary compression rates. Proc. 15th Int. Conf. Soil Mech. Geotech. Engng, Istanbul (in press).

Bjerrum, L. (1972). Embankments on soft ground. State of the art report. Proceedings ASCE specialty conference on performance of earth and earth-supported structures, Purdue University, Vol. 1, pp. $1-54$.

Feng, T. W. (1991). Compressibility and permeability of natural soft clays, and surcharging to reduce settlements. $\mathrm{PhD}$ thesis, University of Illinois at Urbana-Champaign.

Holtz, R. D. \& Broms, B. (1972). 'Long-term loading tests at SkaEdeby, Sweden.' Proceedings ASCE specialty conference on performance of earth and earth-supported structures, Purdue University, Vol. 1, pp. 435-464.

Holtz, R. D., Jamiolkowski, M., Lancellotta, R. \& Pedroni, R. (1991). Prefabricated vertical drains: design and performance, CIRIA Ground Engineering Report: Ground Improvement. Oxford: Butterworth-Heinemann.

Jorgenson, M. B. (1987). Secondary settlements of four Danish road embankments on soft soils. Proc. 9th Eur. Conf. Soil Mech. Found. Engng. 2, 557-560.

Ladd, C. C. (1971). Settlement analysis of cohesive soils, Research Report R71-2. Cambridge, MA: MIT.

Lea, N. D. \& Brawner, C. O. (1963). Highway design and construction over peat deposits in lower British Columbia. Highway Res. Record, No. 7, 1-32.

Mesri, G. \& Feng, T. W. (1991). Surcharging to reduce secondary settlement. Proceedings of the international conference on geotechnical engineering for coastal development: theory to practice, Yokohama, Vol. 1, pp. 359-364.

Mesri, G. \& Godlewski, P. M. (1977). Time- and stress-compressibility interrelationship. J. Geotech. Engng. ASCE 103, No. GT5, 417-429.

Mesri, G., Ullrich, C. R. \& Choi, Y. K. (1978). The rate of swelling of overconsolidated clays subjected to unloading. Géotechnique $\mathbf{2 8}$, No. 3, 281-307.

Mesri, G., Lo, D. O. K. \& Feng, T. W. (1994). Settlement of embankments on soft clays. Proc. Settlement 94, ASCE Geotechnical Specialty Conference, Special Publication No. 40, Vol. 1, pp. 8-76.

Mitchell, J. M. (1981). Soil improvement. State of the art report. Proc. 10th Int. Conf. Soil Mech. Found. Engng. Stockholm 4, 509-565.

Monoi, Y. \& Fuzukawa, E. (1998). Measurement of long-term settlement of highly organic soil improved by preloading. In Problematic soils (eds E. Yanagisawa, N. Moroto and T. Mitachi), Vol. 1, pp. 83-87. Rotterdam: Balkema.

Nash, D. F. T. (2001). Modelling the effects of surcharge to reduce long-term settlement of reclamations over soft clays: a numerical case study. Soils Found. (in press).

Nash, D. F. T. \& Ryde, S. J. (2001). Modelling consolidation accelerated by vertical drains in soils subject to creep. Géotechnique, 51, No. 3, $257-278$.

Navarro, V. \& Alonso, E. E. (2001). Secondary compression of clays as a local hydration process. Géotechnique (in press).

Samson, L. (1985). Postconstruction settlement of an expressway built on peat by precompression. Can. Geotech. J. 22, No. 2, 308-312.

Veder, Ch. \& Prinzl, F. (1983). The avoidance of secondary settlements through overconsolidation. Proc. 8th Eur. Conf. Soil Mech. Found. Engng. 2, 697-706.

Yin, J.-H. \& Graham, J. (1996). Elastic visco-plastic modelling of onedimensional consolidation. Géotechnique 46, No. 3, 515-527. 